\title{
Painting door stories for veterans in palliative care: a ten- year labor of love
}

\author{
Sandra M Walsh ${ }^{1}$, Carmen Prieto $^{2}$ and Maria Olenick ${ }^{1 *}$ \\ ${ }^{1}$ Wertheim College of Nursing and Health Sciences, Florida International University (FIU), Miami, Florida, USA \\ ${ }^{2}$ Nurse Manager Community Living Center, Miami VA, Healthcare System(MVAHS), Miami, Florida, USA
}

\begin{abstract}
Background: Veterans Administration (VA) Hospitals provide long-term care for veterans. A door painting project to enhance the environment in a Community living Center (CLC) at the VA Medical Center in Miami Florida began in 2006 and was completed in 2016. Artist volunteers collaborated with CLCresidents, family members, and staff to plan the door painting images.
\end{abstract}

Aim: To promote comfort of CLC residents, family members, and staff by enhancing the environment, providing increased sociability opportunities, and increasing the opportunity for reminiscence and "way finding" for Dementia residents through the completion of unfinished door paintings on two MVAHS CLC units.

Theoretical framework: Kolcaba'smid-range Comfort Theory guided the door painting initiative (DPI)implemented by artists who interacted with residents, family members, and staff as doors were designed, painted, and critiqued.

Design: Qualitative case study methodologydescribed the door paintings and their context.

Setting/participants: Two CLC units at the MVAHSwith artists, residents, family members, and staff.

Methods: MVAHS staffintroduced artists to residents and family members and assisted artists to communicate with residents and/or family members. Artists implemented the DPI in collaboration with CLC residents to personalize doors through meaningful door paintings. To increase sociability and conversation among residents, staff, and family members, brief stories about the paintings were displayed beside each door painting to describe the painting in participants' words.

Results/Data: Six volunteer artists completed 50 of 60 doors (83\%) in one year. Kolcaba's comfort theory was supported as evidenced by the comments by staff and others. Whenever artists were present, staff and family spoke with them about the improvement in the environment and the increased sociability as participants discussed door paintings with one another.

Results/conclusions: Paintings promoted comfort. Future projects may be implemented in other long term facilities and include determination of outcomes through qualitative and quantitative measures.

\section{Introduction}

Millions of veterans are currently being treated at over 1,700 Veterans Administration (VA) sites throughout the United States. Particularly poignant are the plights of veterans with serious, chronic, or terminal diagnoses who are living out their lives as residents in Community Living Centers (CLCs). The VA has changed the name of theirlong term facilities, previously called nursing homes, to Community Living Centers (CLC). Staff use the word resident instead of patient to describe persons that reside in these centers. Residents are encouraged to decorate their rooms, and pets can visit or live in the CLC. "The mission of a Community Living Center is to restore each Veteran to his or her highest level of well-being. It is also to prevent declines in health and to provide comfort at the end of life [1]. In 2006, the VA Medical Center in Miami, Florida, healthcare staff and a small group of community artists collaborated to complete paintings on a few residents' doors to enhance the environment of two units designated as CLC I and CLC II. A few years later, an artist who was the daughter of a resident and her two daughters (the resident's granddaughters) painted several more doors. Their goal was to paint every resident's door on both units. However, the artist's father died and the daughter and granddaughters found visiting the facility too emotionally painful for them to continue. Thus, several door paintings were left either unfinished or, although primed, remained a blank, white canvas.

\section{Background of the project}

United States veterans are a multifaceted population and culture with very specific and unique sets of health issues including but not limited to mental health and/or behavioral adjustment disorders, substance abuse disorders, post-traumatic stress disorder (PTSD) also previously known as "shell shock" or "combat fatigue", traumatic brain injury, depression, suicide, chronic pain, amputations, hazardous exposure health problems, homelessness, complex deployment, and societal reintegration needs [2]. As mentioned above, veterans residing in Community Living Centers (CLCs) often live with serious, chronic,

Correspondence to: Maria Olenick, Nicole Wertheim College of Nursing and Health Sciences, Florida International University (FIU), Miami, Florida, USA, Tel: 3053487757; E-mail: molenick@fiu.edu

Key words: veterans, palliative care, comfort, art, painting, long term care

Received: September 29, 2016; Accepted: October 27, 2016; Published: November 01, 2016 
or terminal diagnoses and have very little (if any) family support. Roughly a third of long term care residents suffer from depression [3]. Enhancing the environment for veterans who reside in CLCs becomes very essential to make the veterans feel more at "home" and create meaning in their environment and the context in which they reside.

In the fall of 2015 the first author, a nurse researcher, completed a presentation to staff about a research project that involved simple art activities. As she exited the meeting, the second author, a nurse manager of the CLC II unit asked, "Do you happen to also be an artist?" The researcher replied, "Yes, but, (laughter) — but I'm a watercolorist". The manager persevered, "Could you 'try' to paint some of these unfinished doors?'. Researcher, "These doors are painted with acrylics, and I'm not familiar with that medium, but, yes, I will try". (Note important question that follows). "What if I ask the resident or family member or staff what image they would like on the door?" Reply, "Sure, anything to get them involved would be great". The bolded question is important as that question was theory based from the researcher's point of view. A mid-range nursing theory was the theoretical foundation for the painting initiative that followed.

After painting a few doors, patients, family members, and staff began to approach the researcher/artist with suggestions to personalize other doors by painting over images they did not like. Often they had specific requests for the artist to personalize existing paintings or create new images tailored for them. The artist consulted with unit managers for guidance. All agreed that doors staff liked or doors that were signed by an artist would NOT be altered. Any other doors could be "designed" by residents, family members, and staff if the artist were willing. As the project expanded, the researcher/artist recruited additional artists to assist her with the project [4].

Door paintings contributed vibrant colors and images to the otherwise bleak and sterile walls of the long-term care CLCs. In addition to the visual environmental contribution, the door painted images chosen by residents in concert with their families and CLC staff provided opportunity for the residents to reminisce. Reminiscence is a form of psychosocial, non-pharmacologic therapy often used in dementia patients to improve quality of life [5]. Recollection of past events and meaningful memories may be used as a form of communication. Reflection on events, emotions, and relationships correlates with non-pharmacologic cognitive, functional, behavioral, and affective interventions in dementia [5].

\section{Theoretical framework}

Kolcaba's Comfort Theory [6] guided conversations between artists and residents, family members, and staff while doors were designed and painted. Kolcaba defines comfort as, "The immediate experience of being strengthened by having needs for relief, ease, and transcendence met in four contexts (physical, psychospiritual, sociocultural, and environmental); much more than the absence of pain or other physical discomforts" [6]. Kolcaba includes in her definition of comfort needs ... "patients' and families' desire for relief/ease/transcendence in ... sociocultural, and environmental contexts of human experience" [6]. Kolcaba also addresses changes in the environment to increase nurses' comfort [6]. In personal communication with Kolcaba, she discussed that reminiscence and way finding are synonyms for transcendence. She said, ". . . the definition of comfort entails exactly what you are able to achieve with your door paintings" (personal communication via e-mail, September 21, 2016). Kolcaba's theoretical framework was chosen based on results from the researcher's previous studies and the researcher's use of nursing theory to guide her practice, even in the role of an "artist". Kolcaba's comfort theory was considered by the researcher to be an excellent fit for a project designed to enhance the environment and increase the sociability of participants.

The researcher/artist named the painting project as a "Door Painting Initiative" (DPI), that was implemented by an artist but through of the lens of a nurse researcher. As other artists joined the project, the researcher/artist oriented each artist to the theoretical framework. She introduced any new artist to residents and staff. A new artist observed and participated in initial interactions as the researcher/artist explained the DPI to potential participants. After observing such interactions and acknowledging they understood the focus of the project, a new artist decided if she wanted to continue. Throughout the project, artists focused on the concepts of sociability and personalization of the environment as they collaborated with residents, family members, and staff to create the door paintings.

\section{Review of literature}

A literature search from multiple search engines including CINAHL, ERIC, and PsychInfo plus hand searches yielded reports from multidisciplinary art-based projects with a variety of vulnerable groups. Searches were limited to the past 10 years, adults, and in English. Key words used were reminiscence, art, and way finding. Multiple articles about reminiscence and/or art used with persons with dementia were located. No citations were found in which patients/residents or family/ staff directed content of artists' paintings. No matches were found when "veteran(s) or military personnel" were added to search words.

Articles found included designs that ranged from anecdotal evidence, case studies, descriptive, pre-experimental, quasiexperimental, and experimental designs. Examples of arts-based approaches were from art therapy [7,8] occupational therapy [9] nursing practice $[10,11]$, nursing education [12-14], rehabilitation therapy [15], creative expression [16], and a dancer's rehabilitation journey [17] that supported the use of art-based interventions to promote mental and physical health in vulnerable populations.

The Miami City Ballet dancer's story was recently featured in the Miami Herald [17]. Isanusi Garcia Rodriguez had a brain aneurysm at age 35 [17]. During his four year rehabilitation and temporary paralysis of his right side, he used his non-dominant left hand to paint. Rodriguez said, "When I couldn't talk or do anything, I was painting and painting" [17]. Now recovered, he and his mother, also a professional dancer, performed together for the first time at an International Ballet Festival of Miami gala on September 10, 2016.

Additional searches were conducted the phrase "Way-finding in Dementia". One article [18] supported the concept of the DPI to help residents develop a cognitive map through perceptual, cognitive, and contextual cues. No literature was found that described a DPI approach which appears to be unique.

\section{Methods}

Exploratory and descriptive qualitative case study methods were chosen to explore and document the initiative and reveal the essence of the door painting phenomenon $[19,20]$. The context was the CLC environment including residents, family members, staff, and artists that participated in the project. Creswell [19] suggested that a case study can be a "bounded system" in which there is an unusual situation that is described from many perspectives. In the current example, the nurse manager and artist/researcher described how the paintings and "door stories" that were written about the paintings increased sociability and 
personalized the environment [6].

Qualitative case studies are based on the constructivist paradigm concept that recognizes the importance of creating meaning and construction of social reality [20]. A hallmark of this approach is the close collaboration between researcher and participants which enables participants to tell their story. The stories better enable the researcher to understand participants through the memories, remembrances, and reflections shared [20].

The exploratory descriptive case studies used here provided means to explore interventions and describe intervention outcomes within the real life context where the door paintings occurred.

Participants: Participants were voluntary artists, residents, family members, and staff. The scope of the project and numbers of those affected by the project increased over time. The artists focused on residents' requests but included family members and staff when residents' had difficulties communicating verbally. Staff was consulted about preferences for images and gave ideas to artists during the project. For purposes of the remainder of this case study, the residents, family members, and staff will be referred to as participants when readability allows.

The "door painting initiative" (dpi): Artists painted personalized images on the doors of residents' rooms after consulting with participants about their ideas for the content of the paintings. Acrylic paints were used as this medium was appropriate for doors. Acrylic paints have no smell, and have quick drying time. When the door to a room was earmarked for staff, groups, or equipment storage, multiple persons were consulted. In these situations, after receiving suggestions, the artist chose the content of the image that appealed to most.

While the literature review often highlighted the value of patient participation in art making, most residents of these CLC units were unable either physically and/or mentally to participate in the painting process. If not confined to their beds, they were wheelchair bound often with some type of disability to their arms and hands. When residents appeared interested in the process and were able to move one arm and hand, they were invited to assist the artist to paint. Some staff members and/or family members did paint small portions of paintings, and a few residents also added some "strokes". However, most were reluctant to paint but responded quickly when asked for suggestions by the artist. Residents and staff often gathered to watch as artists painted doors. They were encouraged to offer ideas (socialize with each other and the artist) to "improve" the painting. Examples of replies were, "Seems like the boat could be a little bigger ... What about putting some birds in the sky. Maybe the person on the beach could have a dog with him. I think a palm tree needs to be in the background. Could you add a cat somewhere? I would like to see a Jack Russell terrier someplace in the painting. The dog's eyes need to be more golden.” The painting was considered finished when the artist in collaboration with the participants agreed with one another that the participants' ideas had been followed or the artist felt the painting was complete. The artist had the last word. All artists signed their paintings.

Measures: Anecdotal notes were made by the researcher/artist and the CLC II nurse manager as paintings were completed. Notes were also made about the unsolicited comments made by passersby to artists as they painted. The nurse manager of the CLC II who had recruited the researcher/artist in the beginning documented the participants' perceptions about the door paintings. After doors were painted, brief "door stories" were documented to describe the paintings using the residents' or family members' words to capture the meaning behind the paintings.

These "door story" descriptions of paintings were a unique approach that evolved and was not anticipated at the beginning of the project. "Door stories" were posted beside each door painting to promote socialization through conversation about the paintings, to enhance the environment, and to increase the viewer's understanding of the story behind each painting. Residents and family members continued to express pride and appreciation for their painting and door story when they saw artists. Staff and others on the units repeatedly thanked the artists for their "beautiful' work. The researchers choose a variety of paintings to be included in this article to portray the range of images and reactions to the DPI. Eleven paintings and the "door stories" for each painting follow. See illustrations 1-11 and "door stories" 1-11.

1. “Aida” Door Story. "I loved to go fishing, especially on a shrimp boat. I did not have my own boat but I would go on charters. I would catch shrimp with the net. I lived in "la Costa" in Puerto Rico. I named this boat after my sister Aida."

2. "The Buffalo" Door Story. "From the time I was 5 years old living on the farm, I would ask my dad, 'Why can't we have a Buffalo?' as it always symbolized the 'West' to me. I always wanted a Buffalo, and now I have one."

3, "The Pact" Door Story. "The two occupants of this room share a mutual passion for fishing and a love of water. The picture depicts the two veterans on an earlier evening fishing trip on Biscayne Bay with our friends. The name of our boat is RO/TC-our initials".

4. "My Dog Togoh" Door Story. "Togoh was my German Shepherd dog. He lived with me from 1950-1954. He was the watch dog for my business from 1953-1954. I owned a grocery store and a bar in Miami. Togoh was brown and black, his neck was dark brown, his face was black and he had copper colored eyes. He was a good watch dog. He was mindful, quiet and sneaky! He would alert me with 3 barks, the first was soft, the second was soft and the third was ROUGH...that is how I knew there was trouble. Togoh would creep on his hind legs so that no one even knew he was around. Togoh was a good dog."

5. Tropical Fish Colors" Door Story. "I like Tropical fish...these are fresh water. I have had Tropical fish all my life. I have a 90 gallon tank at home. Fish are good for many things: they soothe me, they help me meditate, they help me sleep. They are a "living thing". I wanted to have color in my life"

6. "Miami Starry Night". Door Story. "This door reminds me of meditation and mindfulness.

I think about the negative ions coming from the water, any moving body of water gives off negative ions. Think about the rain, before it starts raining, the air is full of positive ions and that's why you feel sleepy, but after it rains the air is filled with negative ions and that's why you feel rejuvenated."

7. "Daughter and Dad in Paris" Door Story. "This is a painting of me and my Dad walking in a park when I was a little girl and all dressed up. My Dad wanted the park to be near the Eiffel Tower in Paris. He has never been there but always wanted to go. We both love this painting".

8. "The Red Robins" Door Story. "When I was young, hundreds of thousands of red robins would fly down to South Florida for the winter and live in the fig trees. The fig trees were dirtying the city streets and sidewalks with their figs, so the city cut them down. The red robins stopped coming...I miss them.” 
9. "Tropical Sunset" Door Story. "My aunt sent me a postcard with a Tropical Christmas scene one year. It had this beautiful sunset and the palm tree was decorated with lights. We left the lights off so I can have a year round tropical sunset." Note: The four residents that occupied this room agreed on the "Tropical Sunset" image.

10. "Captain Rooster" Door Story. "I like the rooster because he is by himself, just like me. The Rooster reminds me of myself as a Captain of a ship standing at the helm. Name him Captain and make him look tough and fierce just like me"

11."Butterflies and Flowers" Door Story. "I admire butterflies, flying in the lovely green garden with no worries in the world; they are free and that's how I want to be. A butterfly has no problems and eventually that's how I want to be." (Note from artist: Image inspired by photo chosen by the participant from the internet, [21]) (Figures 1-11).

\section{Results}

The DPI project was completed in one year. The artist/researcher discovered that she could not only paint with acrylics but also that she could provide comfort [3] for herself and others through the DPI. Initially, she planned to paint a few doors. However, after four paintings were completed, she found that she was comforted by the socialization with participants and enjoyed the environment. She thought other artists were needed, might enjoy the project, and that they too would find comfort during implementation of the DPI. Five additional artists were recruited. Six artists completed 50 door paintings out of 60

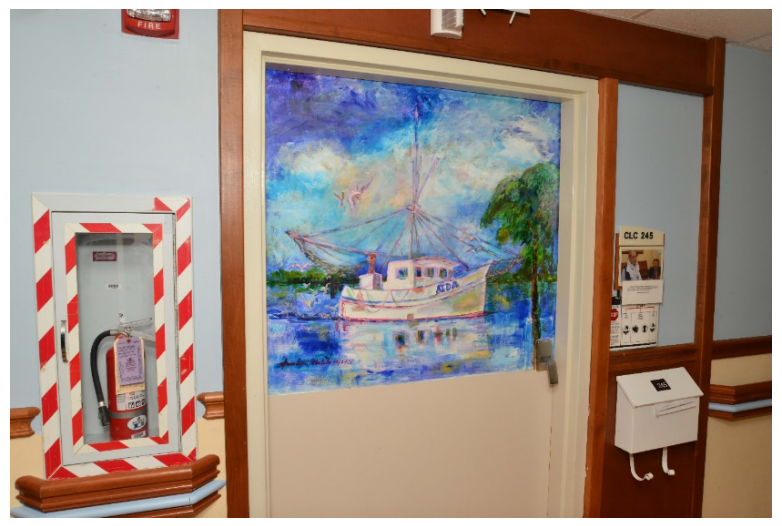

Figure 1. Aida.

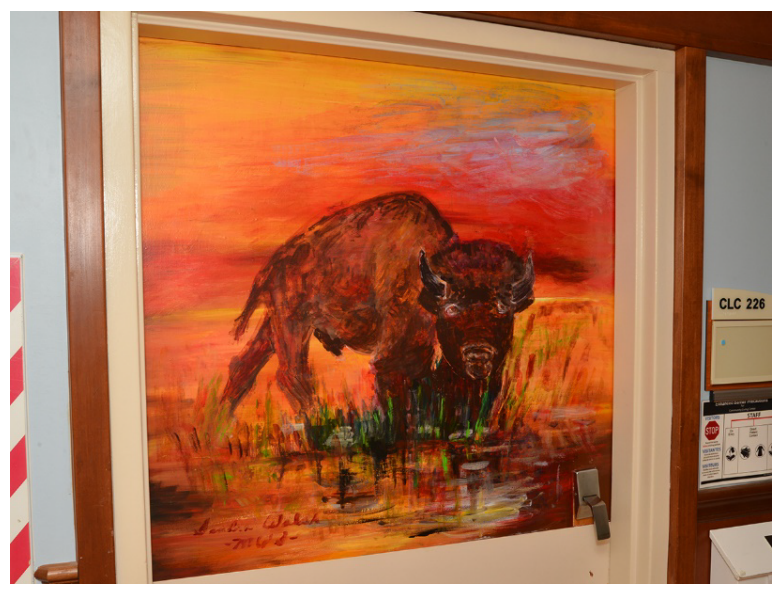

Figure 2. The buffalo.

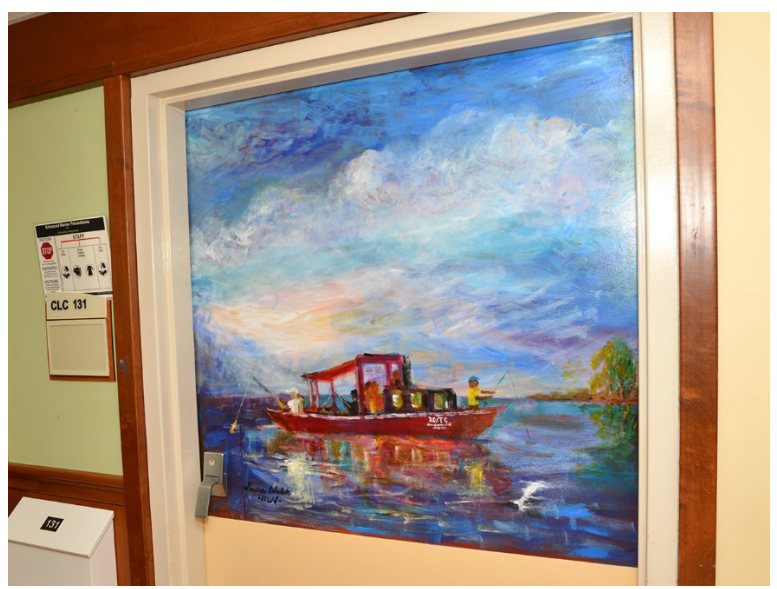

Figure 3. The pact.

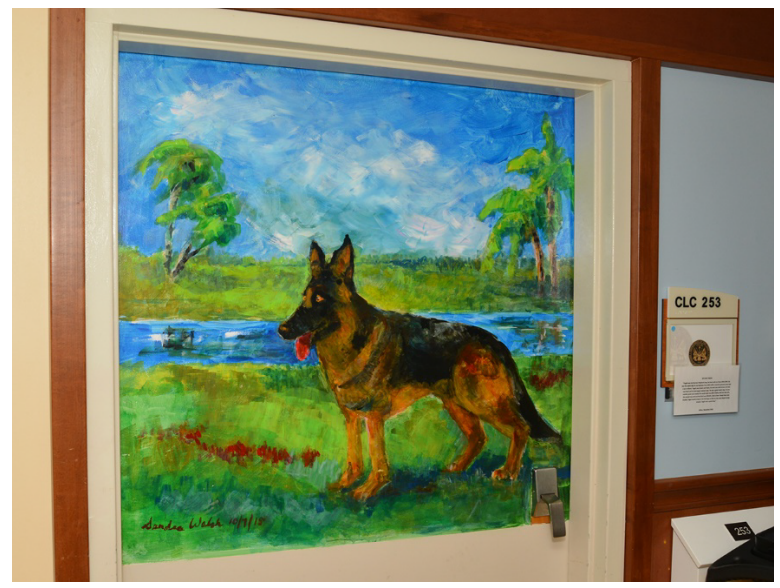

Figure 4. My dog Togoh

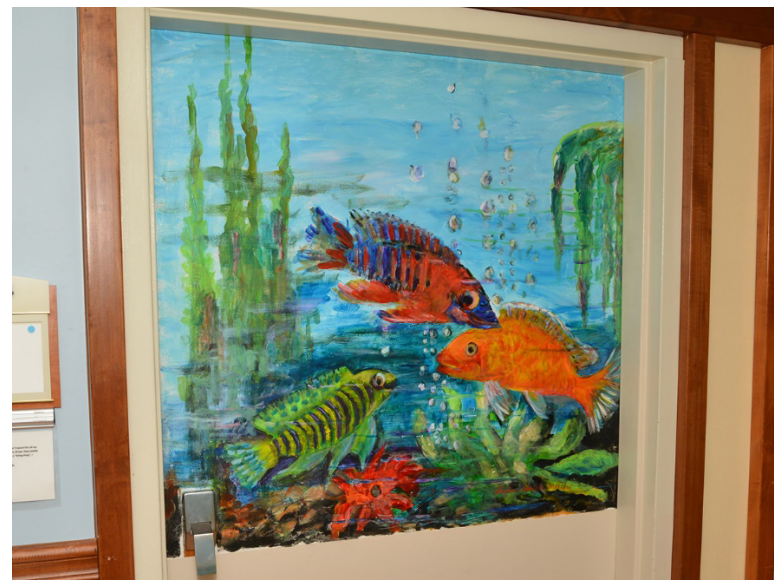

Figure 5. Tropical fish colors.

doors (83\%) in one year. All artists that were introduced to the project continued to paint doors intermittently throughout the year as their schedules permitted. Ten paintings remained untouched because those doors were staff favorites or were signed by previous artists. Painting completion time ranged from 1-12 hours depending on each artist's style, if the painting was new or enhanced, and the number of requests for change made during the painting process.

Kolcaba's comfort theory [6] was supported as evidenced by the comments by staff and others. Whenever artists were present, staff and 


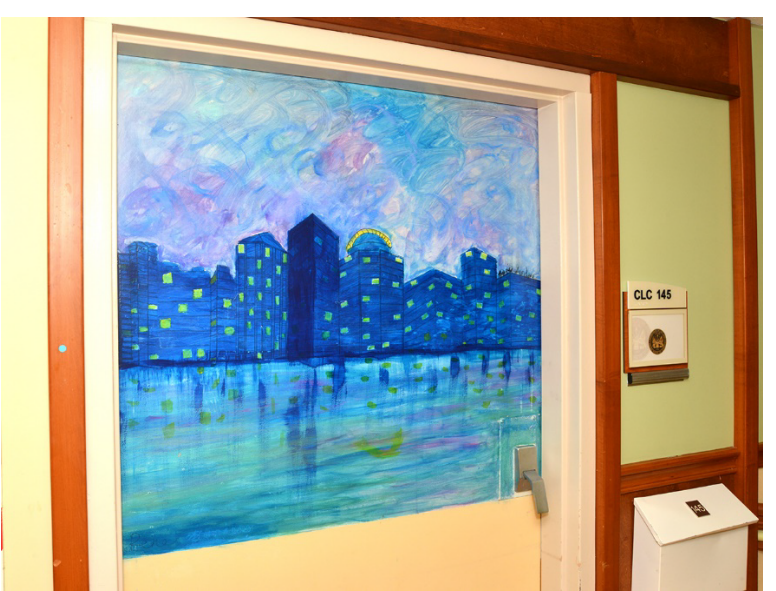

Figure 6. Miami starry night.

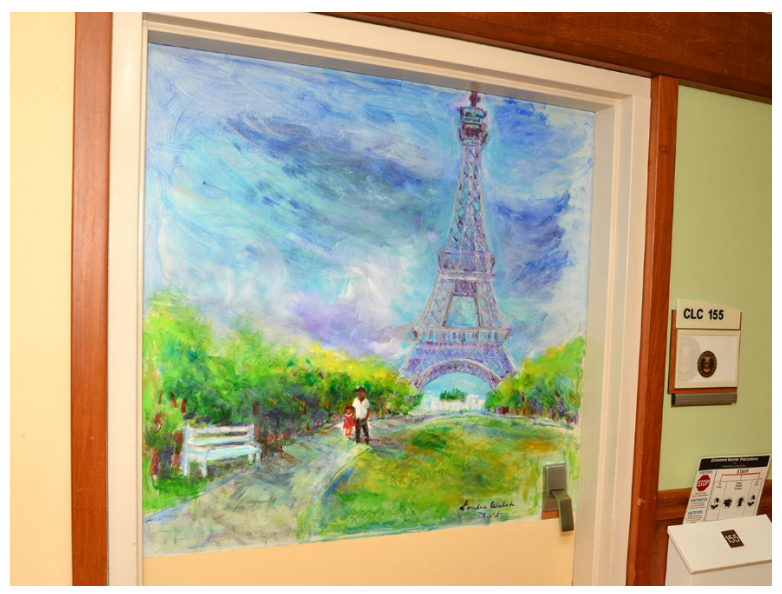

Figure 7. Daughter and dad in Paris.

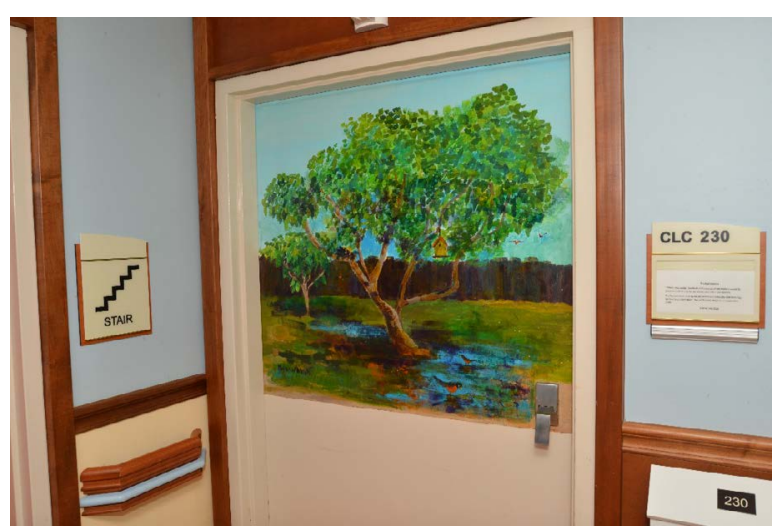

Figure 8. The red robins.

family spoke with them about the improvement in the environment and the increased sociability as participants discussed door paintings with one another. Staff continues to remain engaged. After the project was completed, a nurse stopped one artist and said, "Where is the painting with flowers-I love it and now can't remember which door on what floor? I want to look again. Maybe I could paint something like that". While researchers did not record the number of ongoing positive comments or suggestions offered artists, ideas seemed to increase as participants became more acquainted with the artists and felt comfortable offering their comments and critiques. Socialization between the artist and the resident began when an artist approached them and asked them to tell her more about their door painting (if there was a painting already on the door). Often, they couldn't tell the artist what was on the door. Or, if they did not like the painting, the artist informed them that they could help her design a new painting. In most instances they expressed surprise--even astonishment. "What, are you kidding me? I get to say what goes on the door? "After getting one request for a nude woman or woman in a bikini, artists learned to reply, "Within certain limits, yes." When reactions were, "I don't care,

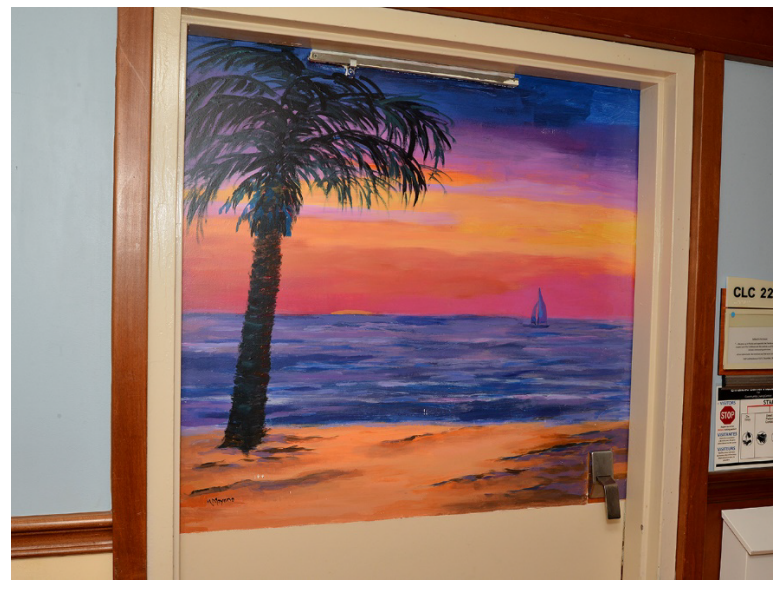

Figure 9. Tropical sunset.

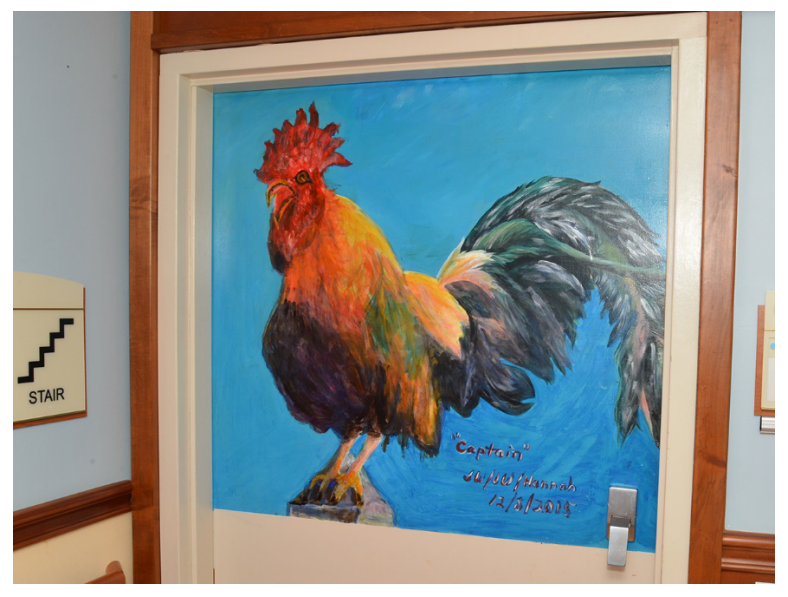

Figure 10. Captain roster.

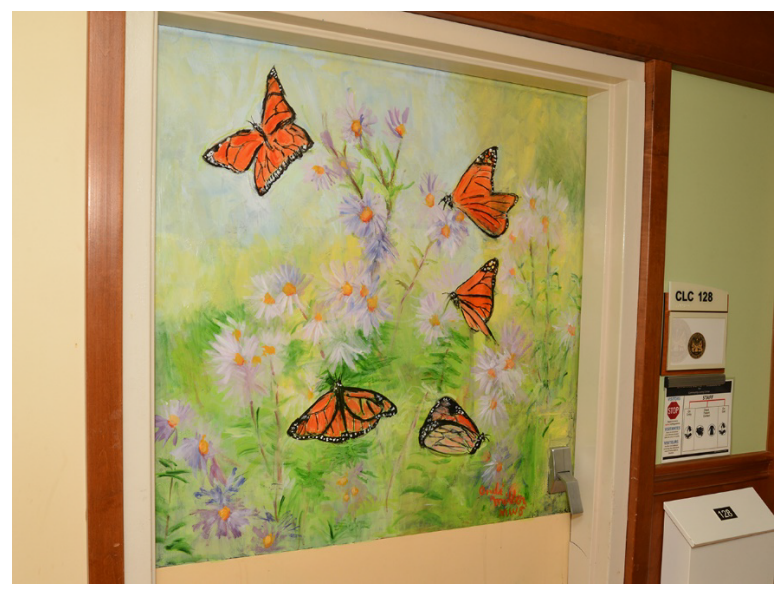

Figure 11. Butterflies and flowers. 
or "I have no idea", the artist prompted, "What image might offer you comfort, solace-or maybe you can recall a cherished memory from childhood or a dream of a place to always wanted to visit?" When the resident could not communicate due to dementia, family members were asked to remember a place or activity that brought joy and comfort to the participant.

Participants then became thoughtful, engaged, and offered multiple suggestions. Artists advised participants that once the painting was signed and varnished there would be no more changes. Participants were offered one last chance to request changes prior to the varnishing. An amusing, unusual last change was requested by one resident for the "The Buffalo" painting (See \#2 door story and painting). The resident, who was described as a loner, began to converse (socialize!) with fellow male residents about "his" Buffalo. They agreed that the artist had not portrayed the male sex of the buffalo distinctly. Last minute "enlargements" were made before varnish was applied.

Decisions about the content of the painting forced sociability when a room was occupied by two or more residents. The artist negotiated with occupants about an acceptable image that would provide comfort to all occupants. An example is illustration \#10, "Tropical Sunset". The "Tropical Sunset" image was agreed on by four residents in a one four bed room. This painting also became a staff favorite.

\section{Discussion}

There were limitations to the project as some residents could not communicate with artists due to their physical or mental health issues. In these instances family members and/or staffwere consulted. Since many residents' health continued to decline, communication with family members and staff about the doors became a positive focus during difficult times. If the scope of the project had been anticipated, perhaps instruments such as Kolcaba's comfort scales could have been completed by participants pre-and post door paintings.

Prior to the project, artists designed their own work. But, during this project, artists were asked to consider the ideas for the content of a painting from participants. While some artists might have not been able to be this flexible, all artists involved in the project cooperated fully. They came to recognize and accept that the socialization between them and participants and the benefits to those that offered ideas far outweighed the finished painting. However, all agreed that the artist that signed the painting would have the last word. Artists ultimately agreed, "If the participant is happy, then I'm happy".

A determination of how many people were and continue to be affected by the DPI is not possible. While patient census on the units averaged 87 and health care personnel numbered 74 , housekeeping staff, visitors, visiting professionals, and in-house professionals from areas such as occupational therapy, music therapy, dieticians, etc. continue to make positive comments to staff and artists regularly. In addition to visitors to the unit, medical and nursing students had clinical rotations at the CLC.

Future plans at different sites may include evaluation surveys from participants after a project is implemented. Such information would increase knowledge about the comfort of residents even when residents cannot actively participate in activities. Kolcaba's comfort scales [6] would be appropriate instruments for a pre-post test quasiexperimental design. A Randomized Clinical Trial (RCT) could be conducted with the project implemented on randomized units with similar populations. The researchers, however, question the time and effort of a RCT since desirable outcomes have already been demonstrated, and no risks can be identified.

Collaborating on a painting was a new experience for the artists. With the focus on participants, artists needed to be flexible, willing to accept ideas from others, and have the ability to interact with residents who have multiple physical and mental health issues. As challenges presented themselves about the content of a painting (when participants requested a figure or an image an artist felt they were unable to paint), artists collaborated with one another, and even painted on each other's paintings. Therefore, on some paintings, the paintings were signed by several artists. Artists accepted or rejected suggestions and encouraged comments/critiques from the participants while painting.

The strengths of the project include the possibility of transferability to other long term care facilities to enhance the environment and to increase socialization. This project offered the opportunity to enhance the quality of the "built" environment and quality of life [19] for residents. Fleming and colleagues [19] discussed that the environment offers the opportunity to enhance useful stimulation and social interaction. Kolcaba's concept of comfort (personal communication, September 21, 2016) includes the environment and nursing interventions that may enhance comfort and which are measurable [6].

Artists agreed that the project brought comfort to them also. While they expected the experience to be positive, they were often surprised at the constant thanks, happiness, and appreciation for the artists' efforts expressed by others. One artist remarked, "The project has helped me more than I ever imagined. I have enjoyed the atmosphere, the dedication of staff, the positive attitude of the veterans, and the diligence of family caregivers." Artists also agreed that other artists throughout the U. S. would benefit as much or more than the participants. One artist stated, "I am proud and thankful for all these residents have done for me and our country. This is the least I could do."

It is anticipated that undergraduate nursing students at Miami's highest research Carnegie designated Florida International University (FIU) will engage in this DPI. Undergraduate (BSN) nursing students will work to enhance communication and socialization of CLC residents, families of residents, and CLC staff as they interact and respond to enhancements in their environment that promote comfort and socialization. Through this DPI opportunity, nursing students will sharpen their own listening and therapeutic communication skills as they work together with CLC residents to express the story behind each door painting. We expect that the DPI will be beneficial to both the FIU students and the veterans in the CLC at MVAHS.

In addition, nurse researchers at FIU are in the process of implementing a pilot project entitled "Art Images Intervention: Mechanisms to Improve Veterans' Comfort". This project will explore the mechanisms and effects of an art images intervention on veterans, their families, and caregivers. The researchers are hopeful this pilot work will lead to funding to support and further research in promotion of comfort for our nation's veterans who deserve the best care possible for all the great sacrifices they have made for our freedom.

\section{Conclusion}

The concepts of socialization and environment found within Kolcaba's Comfort Theory [6] were supported. The use of nursing theories as a base for nursing science is to be encouraged. However, the practice of research and nursing from a theoretical base offers many challenges. Nursing as a professional discipline has not consistently utilized theory to guide nursing research and practice [20,21]. Yet, in 1978, Barbara Carper [22] paved new ways of knowing for nurse 
scientists to conduct science from a holistic nursing perspective through not only our knowledge of empirics but also esthetics, personal knowledge, and ethics. We believe the DPI embodied such an effort.

Internal funding or external funding for artists' time and supplies may be available. If not, most communities have artists' groups whose members would welcome the opportunity to share their talents at healthcare facilities. There would be no cost to the hospital. At this VA, funds were made available from the CLC to provide artists with supplies, but the artists' time was willingly donated. When the project was completed, interested parties met to discuss the impact of the project and how undergraduate nursing students and faculty at FIU may engage in and learn from this unique opportunity to enhance the lives, environments, and comfort of veterans.

When the DPI was completed, artists mentioned that they thought paintings might be improved even after their finished paintings had been varnished. However, as agreed, once participants were satisfied, the paintings would not be changed. Staff consistently remarked that the quality, design, and artistic merit of each painting were not of prime importance. Favorite paintings were not universal as many paintings were liked for different reasons. What was important was the promotion of comfort, sociability, environmental enhancement, and transcendence [3] that the door stories and paintings provided. The chief medical officer concluded, "This project is priceless".

\section{Conflicts of interest}

The authors declare there are no conflicts of interest.

\section{Acknowledgements}

Funding for artists' supplies by CLC at the Miami VA Healthcare System, Florida. Larry Gilstead, VA photographer. Artists: Charlene Weiss, Wendy Gaiter, Mabel Mayan, Rene Sanders, and Andy Miller. CLC I nurse manager, Gaye Belgrade, PhD, RN, ARNP, residents, family members, and staff of CLC I and II.

\section{References}

1. Geriatrics and Extended Care. Retrieved on 9/13/2016 from the website

2. Olenick M, Flowers M, Diaz VJ (2015) US veterans and their unique issues: enhancing health care professional awareness. Adv Med Educ Pract 6: 635-639. [Crossref]

3. Thakur M, Blazer DG (2008) Depression in long-term care. J Am Med Dir Assoc 9: 82-87. [Crossref]

4. Miami Watercolor Society (2016) MWS members and "Door Story Paintings" for veterans at Miami veterans hospital. MWS Newsletter 4

5. Cotelli M, Manenti R, Zanetti O (2012) Reminiscence therapy in dementia: a review. Maturitas 72: 203-205. [Crossref]

6. Kolcaba K (2017) Comfort. In: Peterson SJ, Bredow TS (Eds.), Middle range theories: Application to nursing research and practice 5: 196-211.

7. Huet V (2015) Literature review of art therapy-based interventions for work-related stress. International Journal of Art Therapy 20: 66-76.

8. Thomas-Hertz B (2016) Paint me a memory. Long-term Living 65: 22-25.

9. Mouradian LE, DeGrace BW, Thompson DM (2013) Art-based occupation group reduces parent anxiety in the neonatal intensive care unit: a mixed-methods study. $\mathrm{Am}$ J Occup Ther 67: 692-700. [Crossref]

10. Walsh SM, Lamet AR, Lindgren CL, Rillstone P, Little DJ, et al. (2011) Art in Alzheimer's care: promoting well-being in people with late-stage Alzheimer's disease. Rehabil Nurs 36: 66-72. [Crossref]

11. Walsh SM (2009) Arts at the bedside. In: Sadler BL, Ridenhour A (Eds.), Transforming the healthcare experience through the arts 5: 94-99.

12. Chen S, Walsh SM (2009) Effect of a creative-bonding intervention on Taiwanese nursing students' self-transcendence and attitudes toward elders. Res Nurs Health 32: 204-216. [Crossref]

13. Walsh SM, Chen S, Hacker M, Broschard D (2008) A creative-bonding intervention and a friendly visit approach to promote nursing students' self-transcendence and attitudes toward elders: A pilot study. Nurse Education Today 28: 363-370.

14. Lamet AR, Sonshine R, Walsh SM, Molnar D, Rafalko S (2011) A pilot study to test a creative bonding intervention to promote nursing students attitudes towards taking care of older people. Nurs Res Pract 2011: 537634. [Crossref]

15. Grant M (2002) Guest editorial. Improving quality of life for Department of Veterans Affairs nursing home residents through music and art. J Rehabil Res Dev 42: 2.1

16. Davis R, Therrien BS, Brady T (2009) Working memory cues and way finding in older women. J Appl Gerontol 28: 743-767.

17. Creswell J (2007) Qualitative inquiry and research design: Choosing among five approaches. Thousand Oaks, CA: Sage.

18. Baxter P, Jack S (2008) Qualitative case study methodology: Study design and implementation for novice researchers. Qual Rep 13: 544-559.

19. Fleming R, Goodenough B, Low LF, Chenoweth L, Brodaty H (2016) The relationship between the quality of the built environment and the quality of life of people with dementia in residential care. Dementia (London) 15: 663-680. [Crossref]

20. Andrist K, Nicholas PK, Wolf KA (2006) A history of nursing ideas. Sudbury, MA Jones \& Bartlett.

21. Fawcett J, DeSanto-Madeya S (2013) Contemporary nursing knowledge: Analysis and evaluation of nursing models and theories. Philadelphia: Davis.

22. Carper BA (2013) Fundamental patterns of knowing in nursing. In: Cody WK Philosophical and theoretical perspectives for advanced nursing practice. Burlington, MA: Jones \& Bartlett Learning pp: 23-33.

Copyright: (C2016 Walsh SM. This is an open-access article distributed under the terms of the Creative Commons Attribution License, which permits unrestricted use, distribution, and reproduction in any medium, provided the original author and source are credited. 